\title{
Measuring Conceptual Understanding, Procedural Fluency and Integrating Procedural and Conceptual Knowledge in Mathematical Problem Solving
}

\author{
Ho Thi Minh Phuong \\ ${ }^{1}$ Quy Nhon University, 170 an Duong Vuong Street, Quy Nhon City, Binh Dinh, Vietnam
}

\begin{abstract}
The main aim of this paper is to meassure students' mathematical proficiency on conceptual understanding and procedural fluency, and their ability of integrating procedural and conceptual knowledge in problem solving. Based on the PCK taxonomy (Ho 2018), we design a questionnaire consisting of 12 questions with 22 tasks whose content is focus on linear functions and equations. The collected data is analysed by the statistical software IBM SPSS Statistics 22. Moreover, we use the structural equation modeling (SEM) to study the correlation between these two components of mathematical proficiency and the ability of integrating procedural and conceptual knowledge in problem solving, implemented in IBM SPSS AMOS 24. The findings show that students' mathematical proficiency on procedural fluency on linear functions and equations is higher than that of conceptual understanding, and their ability of integrating procedural and conceptual knowledge is very low. Moreover, these categories have a bi-directional relationship, in which the affection of mathematical proficiency on conceptual understanding to the ability of integrating procedural and conceptual knowledge in problem solving is stronger than on procedural fluency.
\end{abstract}

Keywords: Conceptual knowledge, procedural knowledge, conceptual understanding, procedural fluency, mathematical proficiency, problem solving.

\section{Introduction}

Mathematics education motivates students to become critical and innovative and to cultivate sound reasoning in problem solving. Mathematics education is an active, dynamic and continuous process; activities in mathematics education help students develop their reasoning, think logically, systematically, critically and thoroughly and adopt an objective and open attitude when dealing with problems (Sumarmo 2004). Hence mathematics education forms mathematical proficiency for students.

Conceptual understanding and procedural fluency are two components of the five components (or strands) of mathematical proficiency, the overall goal of K-12 mathematics education as set out by the National Research Council's 1999-2000 Mathematics Learning Study Committee in their report titled Adding It Up: Helping Children Learn Mathematics, published by the National Academy Press in 2001.

According to Jawhara (1995), problem solving activities can open opportunities for students to learn freely. In their own ways, students will be encouraged to investigate, seek for the truth, develop ideas, and explore the problem. Students are also trained not to be afraid to try various ways to solve problems, as well as having the courage to make decisions, act on the decisions and be responsible for the products of the action. The experiences gained through problem solving will help our students to become progressive, creative and ambitious. These features are necessary in order to face the challenges of becoming a developed country based on science and technology (Lim et al. 1999).

In processing mathematical problem solving, the conceptual knowledge is essential to understand the basic concepts in solving them. During the process of mathematical problems solving, the procedural knowledge is required to point out the steps to solve it (Rittle-Johnson, Siegler and Alibali 2001). This is in line with principles and standards for school mathematics, that understanding mathematical concepts and fluency in 
procedures is very significant for students in the learning process. Therefore, the integration of procedural and conceptual knowledge is required in problem solving.

The studies on conceptual understanding and procedural fluency have been recently attracted by many authors (cf. NCTM 2000, 2014, NRC 2001, Jones, Inglis, Gilmore and Hodgen 2013, Crooks and Alibali 2014, Smith, Bill and Raith 2018). The study on problem solving skills in mathematics in relation with conceptual understanding and procedural knowledge has been given in the recent work of Al-Mutawah, Thomas, Eid, Mahmoud and Fateel (2019). However, there are not many works measuring students' ability of integrating procedural and conceptual knowledge in problem solving. The main aim of our paper is to measure students' mathematical proficiency on conceptual understanding and procedural fluency, and also their ability of integrating procedural and conceptual knowledge in problem solving. Moreover, we measure also the correlation between these components of mathematical proficiency and the ability of integrating procedural and conceptual knowledge in problem solving.

\section{Literature review}

\subsection{Conceptual and procedural knowledge and their relationship}

Since the mid-1980s, the most prevalent of these frameworks is one comprised of two major kinds of knowledge, conceptual knowledge and procedural knowledge. Although the origins of this framework are hard to identify precisely, it became widely known after the publication of a book edited by Hiebert (1986).

Conceptual knowledge is typically defined as “... knowledge that is rich in relationships. It can be thought of as a connected web of knowledge, a network in which the linking relationships are as prominent as the discrete pieces of information. Relationships pervade the individual facts and propositions so that all pieces of information are linked to some network". (Hiebert and Lefevre 1986, pp. 3-4).

Procedural knowledge is defined in terms of two kinds of knowledge: One kind of procedural knowledge is a familiarity with the individual symbols of the system and with the syntactic conventions for acceptable configurations of symbols. The second kind of procedural knowledge consists of rules or procedures for solving mathematical problems. Many of the procedures that students possess probably are chains of prescriptions for manipulating symbols (Hiebert and Lefevre 1986, pp. 7-8).

Star and Stylianides (2013) problematized the entangling of type and quality in the use of conceptual knowledge and procedural knowledge. Knowledge quality refers to the way that something is known essentially how well it is understood. Knowledge can be known at a deep level, at a superficial level, and anything in between the two extremes. Deep-level knowledge is linked with understanding, flexibility, evaluation, and critical judgment (De Jong and Ferguson- Hessler 1996). Knowledge type merely refers to what is known. With this distinction, the adjectives "conceptual" and "procedural" demarcate what type of knowledge is being characterized. Thus conceptual knowledge would refer to knowledge of concepts, including principles and definitions; procedural knowledge would refer to knowledge of procedures, including action sequences and algorithms used in problem solving.

Historically, there have been four different theoretical viewpoints on the causal relations between conceptual and procedural knowledge (cf. Baroody 2003, Haapasalo and Kadijevich 2000, Rittle-Johnson and Siegler 1998): Concepts-first, procedures-first, inactivation view and iterative view. The causal relations are said to be bi-directional, with increases in conceptual knowledge leading to subsequent increases in procedural knowledge and vice versa (Baroody 2003, Rittle-Johnson and Siegler 1998, Rittle-Johnson et al. 2001, Rittle-Johnson, Schneider and Star 2015).

According to Rittle-Johnson and Schneider (2015), there is extensive evidence from a variety of mathematical domains indicating that the development of conceptual and procedural knowledge of mathematics is often iterative, with one type of knowledge supporting gains in the other knowledge, which in turn supports gains in the other type of knowledge. Conceptual knowledge may help with the construction, selection, and appropriate execution of problem-solving procedures. At the same time, practice implementing procedures may help students develop and deepen understanding of concepts, especially if the practice is designed to make underlying concepts more apparent. Both kinds of knowledge are intertwined 
and can strengthen each other over time. Moreover, the relations between conceptual and procedural knowledge are bi-directional, but sometimes they are not symmetrical. At times, conceptual knowledge more consistently and strongly supports procedural knowledge than the reverse.

\subsection{Conceptual understanding, procedural fluency and their relationship}

By a report published by the National Research Council (NRC 2001), the mathematical proficiency consists of the following five components or strands, which are necessary for any one to learn mathematics successfully.

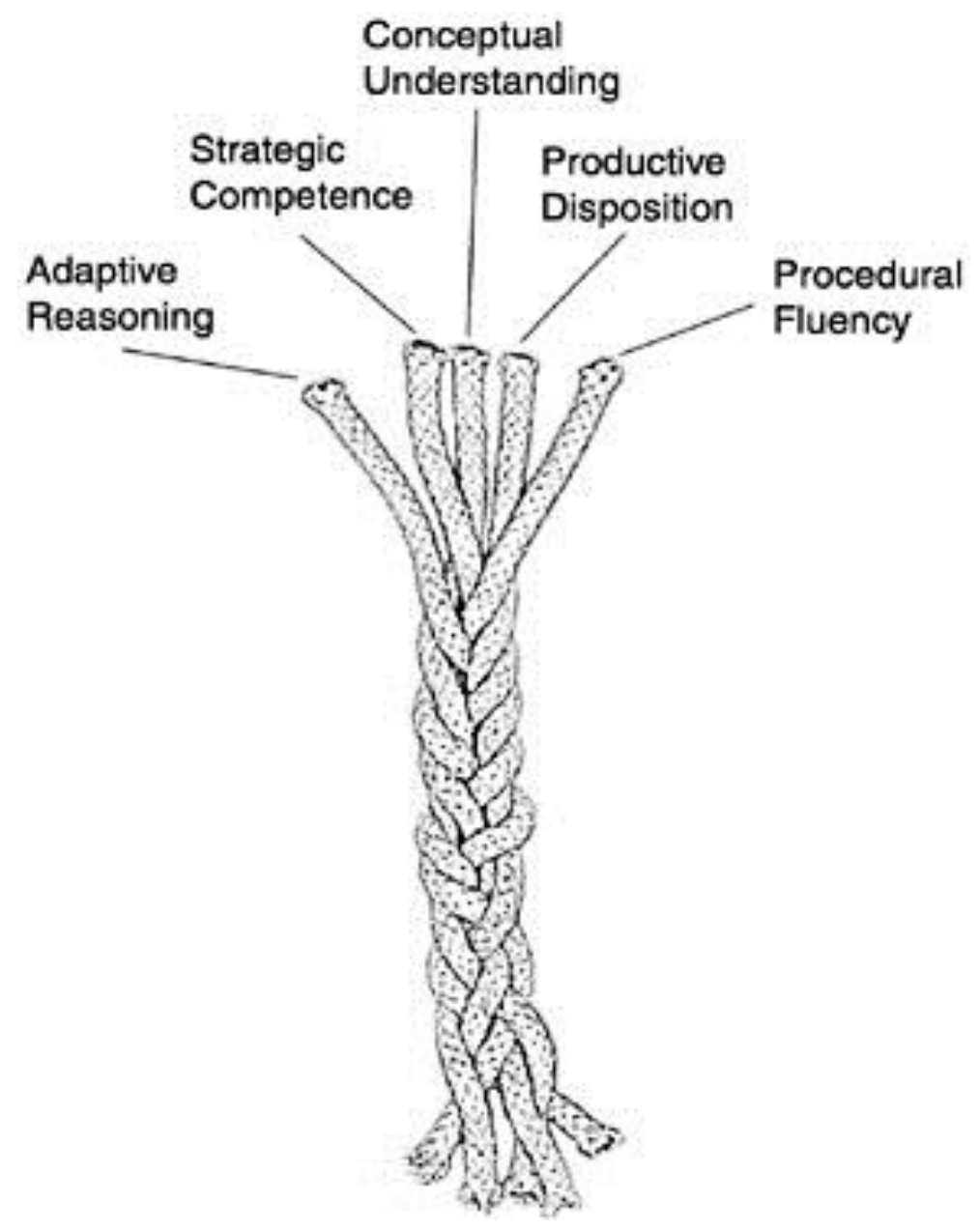

Fig. 1: Five strands of the mathematical proficiency

(1) Conceptual understanding - comprehension of mathematical concepts, operations, and relations;

(2) Procedural fluency - skill in carrying out procedures flexibly, accurately, efficiently, and appropriately;

(3) Strategic competence - ability to formulate, represent, and solve mathematical problems;

(4) Adaptive reasoning - capacity for logical thought, reflection, explanation, and justification;

(5) Productive disposition - habitual inclination to see mathematics as sensible, useful, and worthwhile, coupled with a belief in diligence and one's own efficacy.

These five strands are interwoven and interdependent in the development of proficiency in mathematics (NRC 2001). For the purpose of this paper, we clarify the concepts of conceptual understanding and procedural fluency.

Conceptual understanding refers to the "integrated and functional grasp of mathematical ideas", which "enables them [students] to learn new ideas by connecting those ideas to what they already know." A significant indicator of conceptual understanding is being able to represent mathematical situations in different ways and knowing how different representations can be useful for different purposes. Conceptual understanding helps students avoid many critical errors in solving problems, particularly errors of 
magnitude. Moreover, knowledge that has been learned with understanding provides the basis for generating new knowledge and for solving new and unfamiliar problems (NRC 2001).

Hiebert and Grouws (2007) outline two key aspects of instructional practices that help students develop conceptual understanding: Giving students the opportunity to "struggle" with problems (p. 387), and discussing conceptual relationships "explicitly" (p. 383). These approaches help students develop the ability to transfer their skills and knowledge to new contexts.

Conceptual understanding can be measured in various ways, mainly involving providing definitions, explanations and reasons. Conceptual knowledge in a domain requires usually knowledge of many concepts (Star and Rittle-Johnson 2008, Verschaffel et al. 2009).

Procedural fluency refers to knowledge of procedures, knowledge of when and how to use them appropriately, and skill in performing them flexibly, accurately, and efficiently (NRC 2001).

By the National Council of Teachers of Mathematics (NCTM 2014), Procedural fluency is a critical component of mathematical proficiency. Procedural fluency is the ability to apply procedures accurately, efficiently, and flexibly; to transfer procedures to different problems and contexts; to build or modify procedures from other procedures; and to recognize when one strategy or procedure is more appropriate to apply than another. To develop procedural fluency, students need experience in integrating concepts and procedures and building on familiar procedures as they create their own informal strategies and procedures. Students need opportunities to justify both informal strategies and commonly used procedures mathematically, to support and justify their choices of appropriate procedures, and to strengthen their understanding and skill through distributed practice.

Procedural fluency builds from an initial exploration and discussion of number concepts to using informal reasoning strategies and the properties of operations to develop general methods for solving problems (NCTM 2014). Effective teaching practices provide experiences that help students to connect procedures with the underlying concepts and provide students with opportunities to rehearse or practice strategies and to justify their procedures. Practice should be brief, engaging, purposeful, and distributed (Rohrer 2009). Too much practice too soon can be ineffective or lead to math anxiety (Isaacs and Carroll 1999).

Procedural fluency can be measured by checking the accuracy or the procedure of problem solving. When interested in how flexible procedural knowledge is, researchers assess students' knowledge of multiple procedures and their ability to choose among them to solve problems efficiently (Star and Rittle-Johnson 2008, Verschaffel et al. 2009).

Certainly conceptual understanding and procedural fluency as well as other mathematical strands are strongly interrelated, and there may be many specific skills or types of knowledge that integrate both procedural fluency and conceptual understanding (see e.g. Hiebert and Lefevre 1986, NRC 2001). Understanding makes learning skills easier, less susceptible to common errors, and less prone to forgetting. By the same token, a certain level of skill is required to learn many mathematical concepts with understanding, and using procedures can help strengthen and develop that understanding. Without sufficient procedural fluency, students have trouble deepening their understanding of mathematical ideas or solving mathematics problems. On the other hand, when students practice procedures they do not understand, there is a danger they will practice incorrect procedures, thereby making it more difficult to learn correct ones (NRC 2001). 


\subsection{The PCK taxonomy to assess students' mathematical understanding}

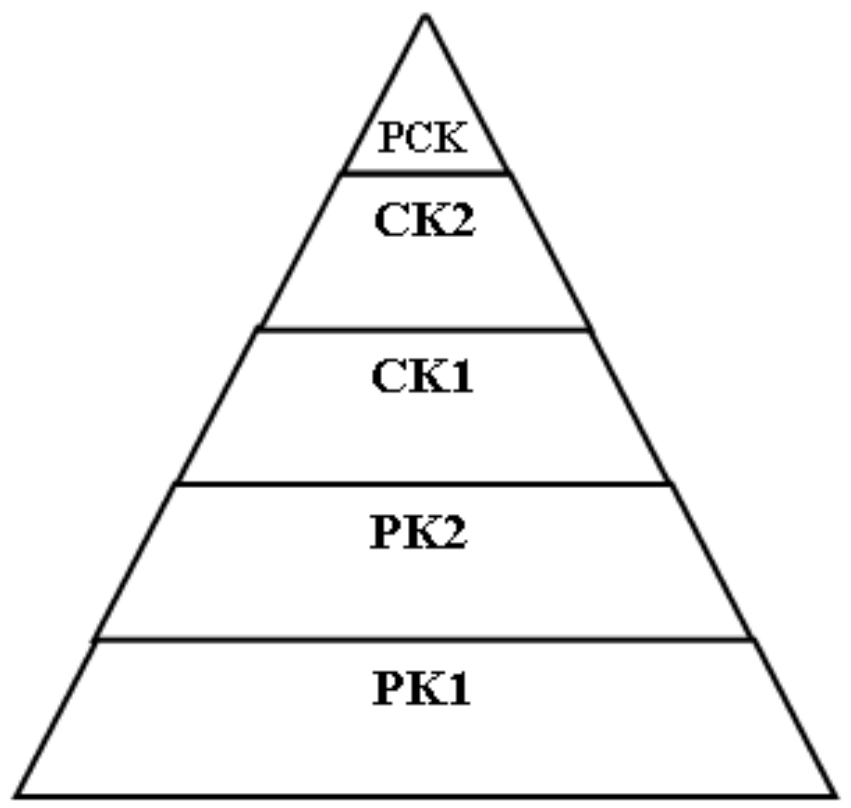

Fig. 2: Five levels of the PCK taxonomy

The PCK taxonomy was proposed recently by the author (Ho 2019), which is a procedural-conceptual based cognitive taxonomy (P stands for Procedural, $\mathbf{C}$ for $\mathbf{C o n c e p t u a l , ~ a n d ~} \mathbf{K}$ for Knowledge). The author used the PCK taxonomy to analyse the mathematics written assessments given at some high schools in Binh Dinh Province (Vietnam), which assess students' mathematical understanding.

This cognitive taxonomy consists of five levels:

- Level 1: (PK1) Familiar procedures

- Level 2: (PK2) Complicated procedures

- Level 3: (CK1) Conceptual understanding

- Level 4: (CK2) Conceptual applying

- Level 5: (PCK) Procedural and conceptual knowledge integration

The content of each level in the PCK taxonomy is described in Table 1, which is arranged from the lowest to the highest level as shown in Fig. 2.

Table 1: Content of levels in the PCK taxonomy

\begin{tabular}{|l|l|}
\hline Categories & Students are able to ... \\
\hline (PK1) Familiar procedures & $\begin{array}{l}\text { Perform simple caculations; apply familiar formulas, } \\
\text { procedures, algorithms. }\end{array}$ \\
\hline (PK2) Complicated procedures & $\begin{array}{l}\text { Perform complicated calculations, high level reasons; link } \\
\text { the different representations of the considered concepts in } \\
\text { solving tasks. }\end{array}$ \\
\hline (CK1) Conceptual understanding & $\begin{array}{l}\text { Recognize and explain the underlying concepts; recognize } \\
\text { the relation of the considered concepts to the other } \\
\text { concepts. }\end{array}$ \\
\hline $\begin{array}{l}\text { (CK2) Conceptual applying } \\
\text { knowledge integration }\end{array}$ & $\begin{array}{l}\text { Apply the considered concept in solving problems; apply } \\
\text { the considered concept to a real situation or to other } \\
\text { concepts. }\end{array}$ \\
\hline & $\begin{array}{l}\text { Integrate procedural knowledge to conceptual knowledge } \\
\text { to solve problems; discover a new situation in which } \\
\text { students need to integrate procedural and conceptual } \\
\text { knowledge to solve. }\end{array}$ \\
\hline
\end{tabular}


In this paper we use the PCK taxonomy as an approach to assess students' conceptual understanding, procedural fluency and their ability of integrating conceptual and procedural knowledge in problem solving.

\section{Research questions}

In this paper we will answer the following research questions.

(1) What is the expression of students' conceptual understanding and procedural fluency? Which kind of proficiency is better?

(2) How is students' ability of integrating procedural and conceptual knowledge in problem solving?

(3) What is the correlation between the conceptual understanding and procedural fluency, and the correlation of those to the ability of integrating procedural and conceptual knowledge in problem solving?

\section{Research methodology}

The participants of this research are Grade 10 students (with total $N=247$ students) at three high schools located in the South Central Coast and Central Highland of Vietnam, including Nguyen Dieu high school (Binh Dinh province), Phan Boi Chau high school (Khanh Hoa province) and Le Loi high school (Kon Tum province).

We apply the PCK taxonomy to design a questionnaire including 12 questions with total 22 tasks whose underlying knowledge focus on linear functions and equations in the curriculum of the textbook Algebra 10 (advanced), in which we insert open-ended questions and realistic problems (see Appendix). Students have to finish all 12 questions in 90 minutes.

We use a 4-point scale to evaluate each task: 4 marks are given for each correct answer, 3 marks for each almost-correct answer, 2 marks for each half-correct answer, 1 mark for each less than one half correct answer, and no mark is given for answers with no content or nonsense. Each student can get a maximum of 88 marks, and each task can get a maximum of 988 marks.

To analyse the collected data, measuring students' understanding mathematics, procedural fluency and ability of integrating conceptual and procedural knowledge in problem solving, we use the statistical software IBM SPSS Statistics 22. Moreover, to study the correlation between three categories, we apply the the confirmatory factor analysis (CFA), a quantitative data analysis method that belongs to the family of structural equation modeling (SEM) techniques (cf. Hox \& Bechger, 1998) and implement in IBM SPSS Amos 24.

CFA detects whether theory-based factors, determined beforehand, are present in the data (cf. Brown 2015). A few studies used CFA in improved shorter versions of scales when the original version failed to meet the established model fit criteria (cf. Slotman, Cramm and Nieboer 2015). Whereas item reduction through exploratory factor analysis does not consider the original factor structure, CFA can produce a more parsimonious structural model that maintains the integrity of the original versions (Larwin and Harvey 2012). Therefore, it was more appropriate to use CFA than exploratory factor analysis (EFA) in this study.

\section{Results}

\subsection{Analyzing of the questionnaire, score of tasks and total score of students}

Firstly we analyse the questionnaire (see Appendix). The questionnaire consists of 12 questions with total 22 tasks (labeled as in Table 2). The distribution of five levels of the PCK taxonomy and the score of each task in the questionnaire is shown in Table 2 (using IBM SPSS Statistics 22).

Table 2: Distribution of five levels of the PCK taxonomy and the mean score of each task

\begin{tabular}{|l|l|l|l|l|l|l|l|}
\hline Tasks & PCK levels & $\mathbf{N}$ & Minimum & Maximum & Sum & Mean & $\begin{array}{l}\text { Mean score } \\
\text { of each level }\end{array}$ \\
\hline Q1 & PK1 & 247 & .00 & 4.00 & 972.00 & 3.9352 & \\
\cline { 1 - 7 } Q2a & PK1 & 247 & .00 & 4.00 & 962.00 & 3.8947 & \multirow{2}{*}{2.64015} \\
\hline Q2b & PK1 & 247 & .00 & 4.00 & 350.50 & 1.4190 & \\
\hline Q3a & PK1 & 247 & .00 & 4.00 & 324.00 & 1.3117 & \\
\hline
\end{tabular}




\begin{tabular}{|c|c|c|c|c|c|c|c|}
\hline Q3b & PK2 & 247 & .00 & 4.00 & 555.50 & 2.2490 & \\
\hline Q4a & PK2 & 247 & .00 & 4.00 & 671.50 & 2.7186 & \\
\hline $\mathrm{Q} 4 \mathrm{~b}$ & PK2 & 247 & .00 & 4.00 & 517.00 & 2.0931 & \\
\hline Q5 & CK1 & 247 & .00 & 4.00 & 472.00 & 1.9109 & \multirow{2}{*}{1.8279} \\
\hline Q6 & CK1 & 247 & .00 & 4.00 & 431.00 & 1.7449 & \\
\hline Q7 & CK2 & 247 & .00 & 7.00 & 626.50 & 2.5364 & \multirow{3}{*}{1.98447} \\
\hline Q8a & CK2 & 247 & .00 & 4.00 & 360.00 & 1.4575 & \\
\hline Q8b & CK2 & 247 & .00 & 4.00 & 484.00 & 1.9595 & \\
\hline Q9 & PCK & 247 & .00 & 4.00 & 423.50 & 1.7146 & \multirow{9}{*}{1.184889} \\
\hline Q10 & PCK & 247 & .00 & 4.00 & 191.00 & .7733 & \\
\hline Q11a & PCK & 247 & .00 & 4.00 & 847.00 & 3.4291 & \\
\hline Q11b & PCK & 247 & .00 & 4.00 & 168.00 & .6802 & \\
\hline Q11c & PCK & 247 & .00 & 4.00 & 468.00 & 1.8947 & \\
\hline Q11d & PCK & 247 & .00 & 4.00 & 20.00 & .0810 & \\
\hline Q12a & PCK & 247 & .00 & 4.00 & 333.50 & 1.3502 & \\
\hline $\mathrm{Q} 12 \mathrm{~b}$ & PCK & 247 & .00 & 4.00 & 171.00 & .6923 & \\
\hline Q12c & PCK & 247 & .00 & 2.00 & 12.00 & .0486 & \\
\hline
\end{tabular}

We have the following observation from Table 2.

(1) Four tasks were designed to agree with the PK1 level, and the same number for tasks agreeing with the PK2 level. The CK1 level contributes in 2 tasks and the number of tasks for the CK2 level is 3. Moreover, we would like to measure students' ability of integrating conceptual and procedural knowledge in problem solving, therefore the PCK level contributes mostly within nine tasks.

(2) The PK1 level scores highest (whose mean score is 2.64015 out of 4), especially, the mean score of the task Q1 is very high with 3.9352 out of 4 . The task Q1 requires solving a linear equation in one variable.

(3) Students had difficulties in solving tasks with respect to the CK1 and CK2 levels (the mean scores are less than 2 out of 4). More than one-half of students have wrong in solving the task Q8a.

(4) The lowest score across all levels is the PCK level whose mean score is 1.184889 out of 4. Especially, almost all students couldn't solve the tasks Q11d and Q12c which are open-ended questions whose contents are realistic problems.

Each student may score maximum 88 marks for 22 tasks in the questionnaire. The mean score over all students is 41.0283 out of 88 . The normality of the distribution of students' total scores is tested by the Kolmogorov-Smirnov test, which is presented in Table 3. Since the significance is greatter than 0.05 , the distribution of students' total scores is normal. 
Table 3: One-Sample Kolmogorov-Smirnov Test

\begin{tabular}{|l|l|l|}
\hline \multicolumn{2}{|l|}{} & Total scores \\
\hline N & & 247 \\
\hline Normal Parameters & a,b & 41.0283 \\
\cline { 2 - 3 } & Mean & 12.07552 \\
\cline { 2 - 3 } Most Extreme Differences & Std. Deviation & .052 \\
\cline { 2 - 3 } & Absolute & .052 \\
\cline { 2 - 3 } & Positive & -.042 \\
\cline { 2 - 3 } & Negative & .052 \\
\hline \multicolumn{2}{|l|}{ Test Statistic } & $.200^{\mathrm{c}, \mathrm{d}}$ \\
\hline Asymp. Sig. (2-tailed) & &
\end{tabular}

a. Test distribution is Normal.

b. Calculated from data.

c. Lilliefors Significance Correction.

d. This is a lower bound of the true significance.

Based on the content of each level in the PCK taxonomy, a priori answer for the first and the second research questions is that students' procedural fluency on linear equations is really better than conceptual understanding, and students' ability of integrating procedural and conceptual knowledge on linear equations in problem solving is very low.

\subsection{Measurement scale}

We use the statistical software IBM SPSS Statistics 22 to analyse the collected data, measuring students' conceptual understanding, procedural fluency and their ability of integrating procedural and conceptual knowledge. Moreover, to study the correlation between these categories, we apply the structural equation modeling (SEM) (cf. Hox and Bechger 1998) and implement by the software IBM SPSS Amos 24.

Procedural fluency on linear equations is measured by the following observed variables:

(1) PF1: Scores on solving linear equations (consisting of four tasks Q1, Q2a, Q2b, Q2c);

(2) PF2: Scores on solving equations that can be reduced to linear equations in one variable (consisting of two tasks Q3a, Q3b);

(3) PF3: Scores on conditions of roots of linear equations in one variable (consisting of two tasks Q4a, Q4b);

(4) PK: The total scores of PF1, PF2 and PF3.

Conceptual understanding on linear equations is measured by the observed variables:

(1) CU1: Scores on recognizing the concept of linear equations in one variable and the interaction of linear functions and linear equations (consisting of two tasks Q5, Q6);

(2) CU2: Scores on applying the concept of equivalent equations (consisting of three tasks Q7, Q8a, Q8b);

(3) CK: The total scores of CU1 and CU2.

Ability of integrating procedural and conceptual knowledge on linear equations in problem solving is measured by the observed variables:

(1) IPCK1: Scores on integrating procedural and conceptual knowledge on linear functions and linear equations to solve problem (consisting of the task Q9);

(2) IPCK2: Scores on integrating procedural and conceptual knowledge on linear equations in one variable to reason the number of roots of equations (consisting of the task Q10);

(3) IPCK3: Scores on integrating procedural and conceptual knowledge on linear functions and linear equations to solve realistic problems (consisting of nine tasks Q11a, Q11b, Q11c, Q11d, Q12a, Q12b, Q12c);

(4) PCK: The total scores of IPCK1, IPCK2 and IPCK3.

The latent variable inferred from the observed variables PF1, PF2, PF3 (resp. CU1, CU2; ICPK1, ICPK2, ICPK3) is denoted by PF (resp. CU; IPCK). The latent variable PF is represented for procedural fluency, while $\mathrm{CU}$ is represented for conceptual understanding, and the variable IPCK is represented for integrating procedural and conceptual knowledge in problem solving. 
We check the reliability of the measurement scale using Cronbach's alpha. The result is shown in Table 4.

\section{Table 4: Cronbach's alpha of the measurement scale}

Item-Total Statistics

\begin{tabular}{|c|c|c|c|c|c|c|}
\hline & $\begin{array}{l}\text { Scale Mean } \\
\text { if Item } \\
\text { Deleted }\end{array}$ & $\begin{array}{l}\text { Scale } \\
\text { Variance if } \\
\text { Item Deleted }\end{array}$ & $\begin{array}{l}\text { Corrected Item- } \\
\text { Total } \\
\text { Correlation } \\
\end{array}$ & $\begin{array}{l}\text { Cronbach's } \\
\text { Alpha if Item } \\
\text { Deleted }\end{array}$ & $\begin{array}{l}\text { Total } \\
\text { Cronbach's } \\
\text { Alpha }\end{array}$ & $\begin{array}{l}\mathrm{N} \text { of } \\
\text { Items }\end{array}$ \\
\hline PF1 & 71.4960 & 517.913 & .581 & .841 & \multirow{11}{*}{.852} & \multirow{11}{*}{11} \\
\hline $\mathrm{PF} 2$ & 76.6012 & 546.827 & .533 & .848 & & \\
\hline PF3 & 77.3138 & 527.349 & .620 & .842 & & \\
\hline PK & 61.2976 & 434.707 & .697 & .826 & & \\
\hline CU1 & 78.4008 & 501.038 & .667 & .834 & & \\
\hline CU2 & 76.0951 & 497.707 & .523 & .841 & & \\
\hline $\mathrm{CK}$ & 72.4393 & 425.470 & .613 & .838 & & \\
\hline IPCK1 & 80.3421 & 536.656 & .506 & .846 & & \\
\hline IPCK2 & 81.2551 & 558.534 & .513 & .852 & & \\
\hline IPCK3 & 73.9211 & 447.170 & .644 & .831 & & \\
\hline PCK & 71.4049 & 387.331 & .698 & .834 & & \\
\hline
\end{tabular}

Corrected item-total correlations of $0.30-0.70$ were considered satisfactory (Ferketich 1991). The total Cronbach's alpha is 0.852, between 0.8 and 0.9, indicating the measurement scale is good (DeVellis 2012).

\subsection{Students'conceptual understanding and procedural fluency}

In this section we continue to answer the first question on students' conceptual understanding and procedural fluency. Firstly we check the reliability of the measurement subscales to measure conceptual understanding and procedural fluency using Cronbach's alphas.

Table 5: Cronbach's alpha of measurement subscale for conceptual understanding

Item-Total Statistics

\begin{tabular}{|l|l|l|l|l|l|l|}
\hline & $\begin{array}{l}\text { Scale Mean } \\
\text { if } \\
\text { Deleted }\end{array}$ & $\begin{array}{l}\text { Scale } \\
\text { Variance if } \\
\text { Item Deleted }\end{array}$ & $\begin{array}{l}\text { Corrected Item- } \\
\text { Total Correlation }\end{array}$ & $\begin{array}{l}\text { Cronbach's Alpha } \\
\text { if Item Deleted }\end{array}$ & $\begin{array}{l}\text { lotal } \\
\text { Cronbach's } \\
\text { Alpha }\end{array}$ & $\begin{array}{l}\text { N } \\
\text { Items }\end{array}$ \\
\hline CU1 & 15.5789 & 67.911 & .786 & .905 & 3 \\
\hline CU2 & 13.2733 & 56.117 & .844 & .815 & $\mathbf{8 9 0}$ & 3 \\
\hline CK & 9.6174 & 26.805 & 1.000 & .746 & & \\
\hline
\end{tabular}

Table 6: Cronbach's alpha of measurement subscale for procedural fluency

Item-Total Statistics

\begin{tabular}{|l|l|l|l|l|l|l|}
\hline & $\begin{array}{l}\text { Scale Mean } \\
\text { if Item } \\
\text { Deleted }\end{array}$ & $\begin{array}{l}\text { Scale } \\
\text { Variance if } \\
\text { Item Deleted }\end{array}$ & $\begin{array}{l}\text { Corrected } \\
\text { Item-Total } \\
\text { Correlation }\end{array}$ & $\begin{array}{l}\text { Cronbach's } \\
\text { Alpha if Item } \\
\text { Deleted }\end{array}$ & $\begin{array}{l}\text { Total } \\
\text { Cronbach's } \\
\text { Alpha }\end{array}$ & $\begin{array}{l}\text { N of } \\
\text { Items }\end{array}$ \\
\hline PF1 & 30.9575 & 49.637 & .743 & .745 & \multirow{2}{*}{} & 4 \\
PF2 & 36.0628 & 62.288 & .661 & .820 & \\
PF3 & 36.7753 & 55.889 & .702 & .782 & \\
PK & 20.7591 & 19.664 & 1.000 & .699 &
\end{tabular}

The Cronbach's alphas are between 0.8 and 0.9, showing that the measurement subscales are good (DeVellis 2012).

Students' scores with respect to observed variables for conceptual understanding and procedural fluency are recorded in Table 7. 
Table 7: Scores on conceptual understanding and procedural fluency

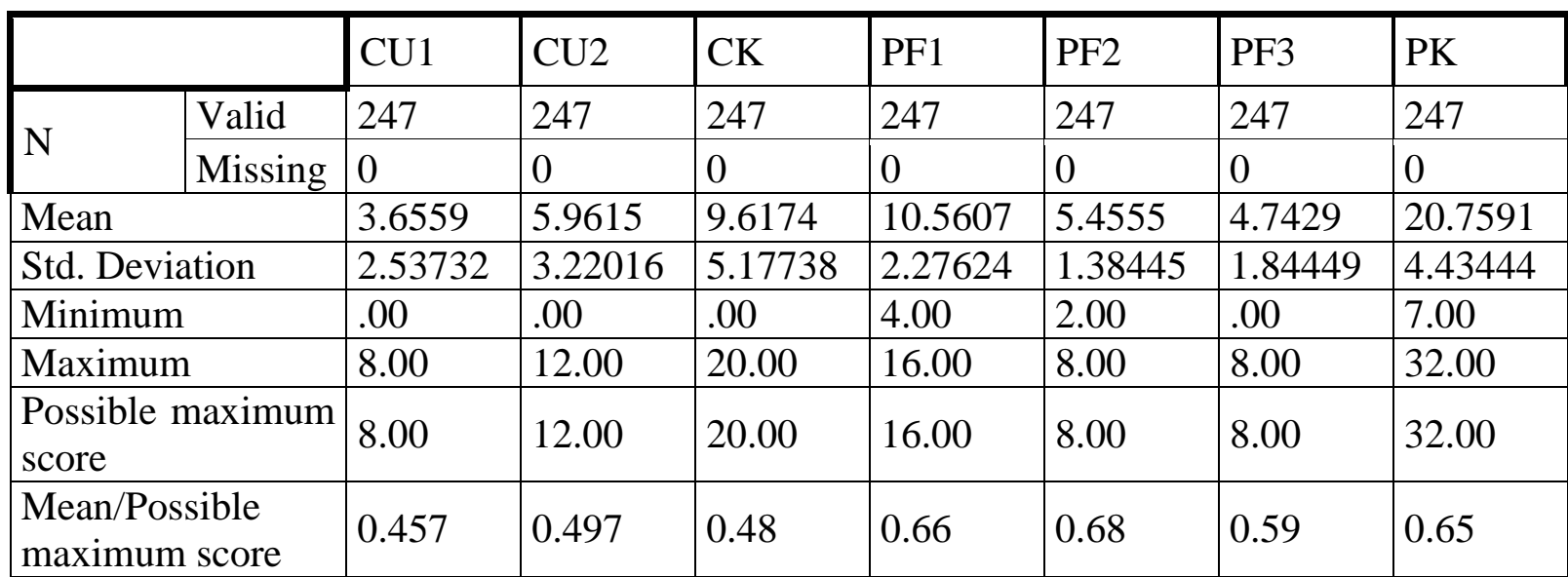

We observe from Table 7 that the mean scores out of possible maximum scores of tasks assessing for procedural fluency is much higher than those for conceptual understanding. In particular, the total mean score of tasks assessing for procedural fluency is 0.65 out of possible maximum, much higher than that for conceptual understanding with 0.48 . It means that students' mathematical proficiency on procedural fluency is much higher than their proficiency on conceptual understanding.

\subsection{Students' ability of integrating procedural and conceptual knowledge in problem solving}

Now we are going to answer the second question. Cronbach's alpha of the measurement subscale for students' ability of integrating procedural and conceptual knowledge in problem solving is 0.778 which are between 0.7 and 0.8, showing that the measurement subscales are acceptable (DeVellis 2012).

Students' scores with respect to observed variables for the ability of integrating procedural and conceptual knowledge in problem solving are shown in Table 8.

Table 8: Scores on integrating procedural and conceptual knowledge in problem solving

\begin{tabular}{|l|l|l|l|l|l|}
\hline \multicolumn{2}{|l|}{} & IPCK1 & IPCK2 & IPCK3 & PCK \\
\hline \multirow{2}{*}{$\mathrm{N}$} & Valid & 247 & 247 & 247 & 247 \\
\cline { 2 - 5 } & Missing & 0 & 0 & 0 & 0 \\
\hline Mean & 1.7146 & .8016 & 8.1356 & 10.6518 \\
\hline Std. Deviation & 1.84471 & .98108 & 4.31376 & 5.87300 \\
\hline Minimum & .00 & .00 & .00 & .00 \\
\hline Maximum & 4.00 & 4.00 & 19.00 & 25.00 \\
\hline Possible maximum score & 4.00 & 4.00 & 36.00 & 44.00 \\
\hline $\begin{array}{l}\text { Mean/Possible maximum } \\
\text { score }\end{array}$ & 0.43 & 0.20 & 0.226 & 0.24 \\
\hline
\end{tabular}

It is clear to observe from Table 8 that the mean scores out of possible maximum scores of tasks assessing for the ability of integrating procedural and conceptual knowledge are very low, with the total mean score is 0.24 out of the possible maximum score. In particular, the mean scores on tasks assessing for realistic problem solving are low, where the maximum score of the variable IPCK3 is even around one-half of the possible maximum score. 


\subsection{Correlation between three categories}

In this section we answer the third research question, studying the correlation between conceptual understanding, procedural fluency and ability of integrating procedural and conceptual knowledge in problem solving. Our method is to apply the structural equation modeling (SEM). The general SEM model can be divided into two sub-models: measurement model and structural model.

A measurement model identifies the relationship between observed variables and the latent variables and provides the basic structure for measuring the latent variables (Byrne 2009). A total of eight observed variables were used to measure the three latent variables in this study. The measurement model for three latent variables is presented in Fig. 2.
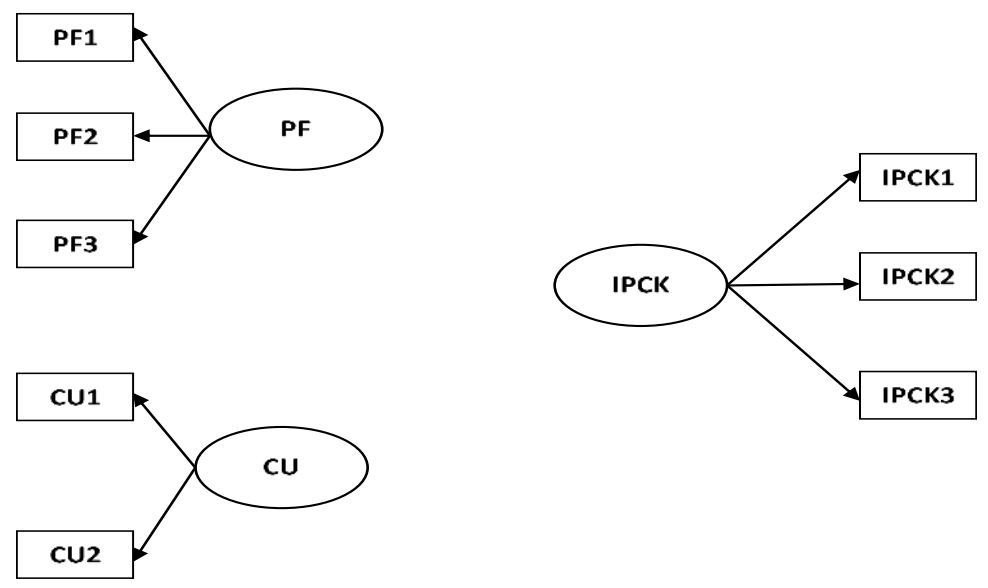

Fig. 2: Measurement model for latent variables

A structural model (also called a latent variable model) determines the relationship between potential variables. Accordingly, it determines the way of direct or indirect effects between the latent variables in the model (Byrne 2009). In this study we propose the bi-directional correlation between latent variables (Baroody 2003, Rittle-Johnson and Siegler 1998, Rittle-Johnson et al. 2001, Rittle-Johnson, Schneider and Star 2015, Rittle-Johnson and Schneider 2015, Hiebert and Lefevre 1986, NRC 2001) (see Fig. 3).

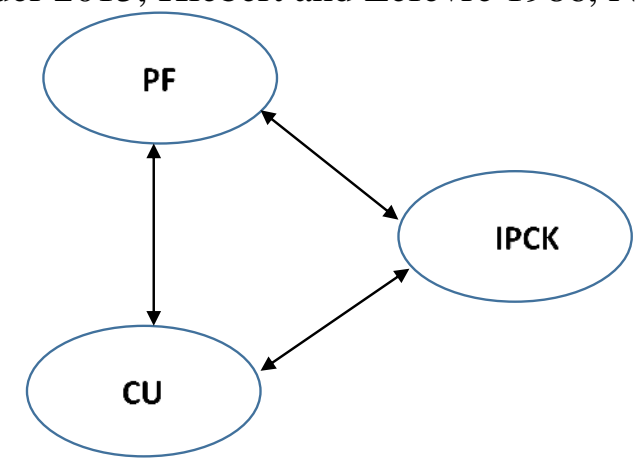

Fig. 3: Structural model

We implement the CFA using a maximum likelihood estimator to assess the validity of the hypothesized factor structure and identify the optimal model. We evaluated the goodness-of-fit using the $\chi^{2} / \mathrm{df}$ ratio, comparative fit index (CFI), Tucker-Lewis index (TLI), goodness of fix index (GFI), and the root mean square error of approximation (RMSEA). The model fit was considered acceptable if the $\chi^{2} / \mathrm{df}$ ratio was lower than 3, the RMSEA was lower than 0.05, and all CFI, TLI, GFI measures were higher than 0.90 (Hair et al. 2010). 
Table 9: Unstandardized regression weights

\begin{tabular}{|l|l|r|}
\hline & & Estimate \\
\hline$<---$ & PF & 1.000 \\
\hline$<---$ & PF & 1.650 \\
\hline$<---$ & PF & 1.512 \\
\hline$<---$ & IPCK & 1.000 \\
\hline$<---$ & IPCK & .522 \\
\hline$<---$ & IPCK & 2.396 \\
\hline$<---$ & CU & 1.000 \\
\hline$<---$ & CU & 1.234 \\
\hline
\end{tabular}

Table 10: Model validity measures

\begin{tabular}{|c|c|c|c|c|c|c|c|}
\hline & CR & AVE & MSV & $\operatorname{MaxR}(\mathbf{H})$ & PF & IPCK & CU \\
\hline PF & 0.720 & 0.463 & 0.503 & 0.726 & $\mathbf{0 . 6 8 0}$ & & \\
\hline IPCK & 0.680 & 0.415 & 0.503 & 0.680 & $0.709 * * *$ & $\mathbf{0 . 6 4 4}$ & \\
\hline CU & 0.798 & 0.674 & 0.284 & 0.959 & $0.533 * * *$ & $0.509 * * *$ & $\mathbf{0 . 8 2 1}$ \\
\hline
\end{tabular}

Output of the CFA analysis of the collected data implemeted in IBM SPSS AMOS 24 were presented in Fig. 4. We have the following observation from Fig. 4.

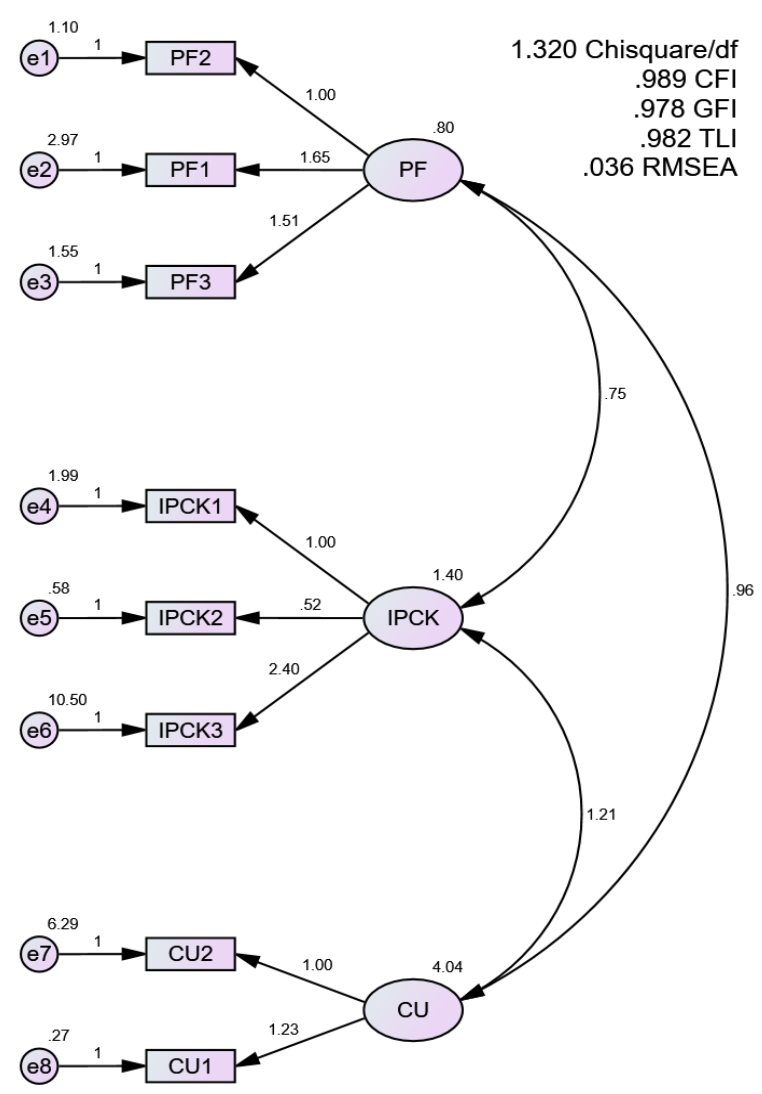

Fig. 4: Unstandardized estimates

(1) $\chi^{2} / \mathrm{df}=1.320<3, \mathrm{RMSEA}=0.036<0.05, \mathrm{CFI}=0.989>0.9, \mathrm{TLI}=0.982>0.9, \quad$ GFI $=0.978>0.9$. Hence the model fit is acceptable. 
(2) The unstandardized regression weights between observed and latent variables are all greater than 0.5 (see Table 9), which indicates that the measurement model is acceptable (cf. Gerbring and Anderson 1988, Hair et al. 2010).

(3) The convergent validity was evaluated using the Average Variance Extracted (AVE). It was considered adequate if AVE $\geq 0.50$ (Fornell and Larcker 1981). However, Malhotra and Dash (2016) argued that AVE is often too strict, and reliability can be established through Composite Reliability (CR) alone.

The model validity measures is shown in Table 10. For the latent variable CU, the AVE is greater than 0.5 and the CR is greater than 0.7 , showing that the convergence validity of CU is good. While the CR of PF is greater than 0.7, that of IPCK is smaller than 0.7. Moreover, the AVE of both variables PF and IPCK is smaller than 0.5. This indicates that the convergence validity of PF and IPCK is not good.

(4) Covariances between the latent variables are presented in Table 11. All regression weights are greater than 0.5, indicating that the bi-directional correlation between three categories is confirmed. Moreover, comparison the regression weights between latent variables shows that the affection of conceptual understanding on the ability of integrating procedural and conceptual knowledge is stronger than that of procedural fluency.

\section{Table 11: Covariances between the latent variables}

\begin{tabular}{|l|l|l|r|r|r|r|r|}
\hline & & & Estimate & S.E. & C.R. & P & Label \\
\hline PF & $<->$ & IPCK & .752 & .137 & 5.479 & $* * *$ & \\
\hline PF & $<-->$ & CU & .960 & .225 & 4.261 & $* * *$ & \\
\hline IPCK & $<-->$ & CU & 1.208 & .293 & 4.125 & $* * *$ & \\
\hline
\end{tabular}

\section{Discussion and Conclusion}

The findings show that students' mathematical proficiency on conceptual understanding is not high, with the total mean score of the observed variable CK is less than one-half out of the possible maximum score. The mathematical proficiency on procedural fluency is better, whose total mean score of the observed variable PK is 0.65 . However the mean scores on tasks assessing for complicated procedures (corresponding to the PK2 level of the PCK taxonomy) are not high, with 0.59 out of the possible maximum scores (see Table 7).

Students' ability of integrating procedural and conceptual knowledge in problem solving is very low, with the total mean score of the observed variable IPCK is just 0.24 out of the possible maximum, in which the scores on tasks assessing for ability of integrating procedural and conceptual knowledge in realistic problem solving are very low (see Table 8).

All the regression weights between three latent variables are greater than 0.5 , indicating that the mathematical proficiencies on conceptual understanding and procedural fluency have a bi-directional relationship, and they have also a bi-directional relationship to the ability of integrating procedural and conceptual knowledge in problem solving. Moreover, the mathematical proficiency on conceptual understanding affects to the ability of integrating procedural and conceptual knowledge in problem solving is stronger that of procedural fluency.

These findings suggest that teachers should pay more attention and more carefully on concept-based teaching for students in the classroom. This helps students to learn new ideas by connecting those ideas to what they already know, to be able to represent mathematical situations in different ways and knowing how different representations can be useful for different purposes, to avoid many critical errors in solving problems, particularly errors of magnitude. Hence, this helps students to improve their proficencies on conceptual understanding. Moreover, it is important to give more problem-solving tasks, especially tasks on realistic problems, for students to solve in the classroom and also at home, which helps student to improve their ability of integrating procedural and conceptual knowledge. On the other hand, the PCK taxonomy is an effective tool to assess students' mathematics understanding, both on procedural and conceptual aspects of knowledge, and also on the integrating of two kinds of knowledge in problem solving. Therefore, we suggest teachers to use this useful tool to design tasks and to assess students' mathematical proficiency. 
The author would like to express her deep gratitude to Dr. Tran Vui (Hue University's College of Education, tranvui@yahoo.com) for his suggestion for the idea of this paper.

\section{References}

[1.] Al-Mutawah MA, Thomas R, Eid A, Mahmoud EY \& Fateel MJ (2019) Conceptual Understanding, Procedural knowledge and Problem-Solving Skills in Mathematics: High School Graduates Work Analysis and Standpoints. International Journal of Education and Practice 7 (3): 258-273.

[2.] Baroody AJ (2003) The Development of Adaptive Expertise and Flexibility: The Integration of Conceptual and Procedural Knowledge. In: Baroody AJ and Dowker A (Ed) The Development of Arithmetic Concepts and Skills: 1-34.

[3.] Blum W, Leiss D (2007) How do students and teachers deal with modelling problems? Haines, C. et al. (ur.), Mathematical Modelling: Education, Engineering and Economics, Chichester, Horwood: 222-231.

[4.] Brown TA (2015) Confirmatory factor analysis for applied research. Guilford Publications.

[5.] Byrne BM (2009) Structural Equation Modeling With AMOS: Basic Concepts, Applications, and Programming. Second Edition. Routledge, New York: United States of America.

[6.] Crooks NM and Alibali MW (2014) Defining and measuring conceptual knowledge in mathematics. Developmental Review 34: 344-377.

[7.] DeVellis RF (2012) Scale development: Theory and applications. Los Angeles: Sage. pp. 109-110.

[8.] Ferketich S (1991) Focus on psychometrics. Aspects of item analysis. Research in Nursing \& Health 14(2): 165-168.

[9.] Gerbing DW and Anderson JC (1988) An Updated Paradigm for Scale Development Incorporating Unidimensionality and Its Assessment. Journal of Marketing Research 25 (2): 186-192.

[10.] Hair J, Black W, Babin B and Anderson R (2010) Multivariate data analysis (7th ed.): PrenticeHall, Inc. Upper Saddle River, NJ, USA.

[11.] Hiebert $\mathrm{J}$ and Lefevre $\mathrm{P}$ (1986) Conceptual and procedural knowledge in mathematics: An introductory analysis. In: Hiebert J (Ed) Conceptual and procedural knowledge. The case of mathematics (pp. 1-27). Hillsdale: Lawrence Erlbaum Associates.

[12.] Hiebert J and Grouws DA (2007) The effects of classroom mathematics teaching on students' learning. In: FK Lester (Ed) Second handbook for research in mathematics teaching and learning: A project of the National Council of Teachers of Mathematics (pp. 371-404). Charlotte, NC: Information Age Publishing.

[13.] Ho TMP (2019) On the Procedural-Conceptual Based Taxonomy and Its Adaptation to the MultiDimensional Approach SPUR to Assess Students' Understanding Mathematics. American Journal of Educational Research 7(3): 212-218.

[14.] Hox JJ and Bechger TM (1998) An introduction to structural equation modeling. Family Science Review 11: 354-373.

[15.] Jawhara $\mathrm{T}$ (1995) Problem solving and creative thinking in education. New York: Oxford University Press language.

[16.] Jones I, Inglis M, Gilmore C and Hodgen J (2013) Measuring conceptual understanding: The case of fractions. In: Lindmeier AM and Heinze A (Ed) Proceedings of the 37th Conference of the International Group for the Psychology of Mathematics Education (Vol. 3, pp. 113-120). Kiel, Germany: IGPME.

[17.] Kline RB (2011) Principles and practice of structural equation modeling. New York: Guilford Press.

[18.] Isaacs AC and Carroll WM (1999) Strategies for basic-facts instruction. Teaching Children Mathematics 5(9): 508-515.

[19.] Larwin K, Harvey M (2012) A demonstration of a systematic item-reduction approach using structural equation modeling. Practical Assessment, Research \& Evaluation 17(8): 1-19.

[20.] Lim KH, Foo LK, Nagarajah L, Mohd MN and Murshidi NK (1999) The ability of new teachers in non-routine the problem solve math. Collections of Research Science Teachers College in Bintulu: 57-87. 
[21.] Malhotra NK, Dash S (2011) Marketing Research an Applied Orientation. London: Pearson Publishing.

[22.] National Council of Teachers of Mathematics (2000) Principles and standards for school mathematics. Reston VA: Author.

[23.] National Council of Teachers of Mathematics (2014) Principles to actions: Ensuring mathematical success for all. Reston VA: Author.

[24.] National Research Council (2001) Adding it up: Helping children learn mathematics. Kilpatrick J, Swafford J and Findell B (Ed) Mathematics Learning Study Committee, Center for Education, Division of Behavioral and Social Sciences and Education. Washington, DC: National Academy Press.

[25.] Rittle-Johnson B and Alibali MW (1999) Conceptual and procedural knowledge of mathematics: Does one lead to the other? Journal of Educational Psychology 91(1): 175-189.

[26.] Rittle-Johnson B, Siegler RS and Alibali MW (2001) Developing conceptual understanding and procedural skill in mathematics: An iterative process. Journal of Educational Psychology 93: 346.

[27.] Rittle-Johnson B and Schneider M (2015) Developing conceptual and procedural knowledge in mathematics. In: Cohen Kadosh R and Dowker A (Ed), Oxford handbook of numerical cognition, 1102-1118, UK: Oxford University Press.

[28.] Rittle-Johnson B, Schneider M and Star JR (2015) Not a One-Way Street: Bidirectional Relations Between Procedural and Conceptual Knowledge of Mathematics. Educ Psychol Rev.27: 587-597.

[29.] Rohrer D (2009) The effects of spacing and mixed practice problems. Journal for Research in Mathematics Education 40(1): 4-17.

[30.] Schneider M and Stern E (2010) The developmental relations between conceptual and procedural knowledge: A multimethod approach. Developmental Psychology, 46(1): 178-192.

[31.] Slotman A, Cramm JM, Nieboer AP (2015) Validation of the Dutch Aging Perceptions Questionnaire and development of a short version. Health and quality of life outcomes, 13(1):1.

[32.] Smith M, Bill V and Raith ML (2018) Promoting a Conceptual Understanding of Mathematics (pp. 36-43). Mathematics Teaching in the Middle School, 24 (1): 36-43.

[33.] Sumarmo U (2004) Independent learning: What, why and how develop among students. Bandung: Indonesia University of Education Press.

[34.] Star JR and Rittle-Johnson B (2008) Flexibility in problem solving: The case of equation solving. Learning and Instruction, 18(6): 565-579.

[35.] Star JR and Stylianides GJ (2013) Procedural and conceptual knowledge: Exploring the gap between knowledge type and knowledge quality. Canadian Journal of Science, Mathematics and Technology Education, 13(2): 169-181.

[36.] Verschaffel L, Luwel K, Torbeyns J and Van Dooren W (2009) Conceptualizing, investigating, and enhancing adaptive expertise in elementary Mathematics education. European Journal of Psychology of Education, 24(3): 335-359.

\section{Appendix. The Questionnaire}

Question 1. Solve the equation $580-x-(500-0,6 x)=0$.

Question 2. Given the equation $500-0,6 x-y=0$.

a) Find the value of $y$ for $x=6$.

b) How change is the value of $y$ when the value of $x$ increased by 1?

c) Solve the given equation.

Question 3. Solve the following equations.

a) $\frac{2 x}{x-3}+\frac{5 x+3}{x+3}=7$.

b) $|2 x-1|=x-1$.

Question 4. Given the equation $m^{2} x-m=9 x-3$ with $m \in \square$. Find all values of the parameter $m$ such that the following holds.

a) The given equation has a unique root;

b) The given equation holds for all $x \in \square$. 
Question 5. Given the linear equations $a x+b=0$ and $c x+d=0$. Is the equation $a x+b=c x+d$ a linear equation in one variable? Explain.

Question 6. Given two linear equations $\mathrm{y}=(\mathrm{m}+1) \mathrm{x}+1$ and $\mathrm{y}=\left(3 \mathrm{~m}^{2}-1\right) \mathrm{x}+\mathrm{m}$, where $m \in \square$. Find all values of the parameter $m$ such that these equations have infinitely common roots.

Question 7. To solve the equation $x+\sqrt{x-2}=1+\sqrt{x-2}$, the steps in the argument of An as follows. Because two sides of the equation have the same quantity $\sqrt{x-2}$, cancelling this quantity in both sides to obtain an equivalent equation $x=1$. Is this argument correct? Expain.

Question 8. Are the following statements correct? Expain.

a) $|3 x-2|=x-3 \Rightarrow(3 x-2)^{2}=(\mathrm{x}-3)^{2}$.

b) $\sqrt{x}(x+2)=\sqrt{x} \Leftrightarrow x+2=1$.

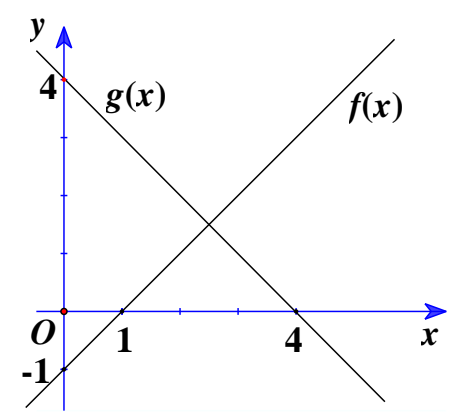

Fig. 5: Graphs of $y=f(\mathrm{x})$ and $y=g(\mathrm{x})$

Question 9. Given two functions $y=f(\mathrm{x})$ and $y=g(x)$ whose graphs as in Fig. 5. Find the root of the equation $f(x)+2 \mathrm{~g}(\mathrm{x})-5=0$.

Question 10. Find all values of the parameter $m \in \square$ such that the equation $\frac{2 m x-1}{\sqrt{x-1}}-2 \sqrt{x-1}=\frac{m+1}{\sqrt{x-1}}$ has a root.

Question 11. For health reasons people should limit their efforts, for instance during sports, in order not to exceed a certain heartbeat frequency.

For years the relationship between a person's recommended maximum heart rate and the person's age was described by the following formula:

Recommended maximum heart rate $=220-$ age .

Recent research showed that this formula should be modifed slightly. The new formula is as follows:

Recommended maximum heart rate $=208-(0.7 \times$ age $)$.

a) Complete the following table on recommended maximum heart rate.

\begin{tabular}{|l|l|l|l|l|l|}
\hline Age $($ in year) & 9 & 12 & 15 & 18 & 21 \\
\hline $\begin{array}{l}\text { Recommended maximum } \\
\text { heart rate (old formula) }\end{array}$ & 211 & 208 & 205 & 202 & 199 \\
\hline $\begin{array}{l}\text { Recommended maximum } \\
\text { heart rate (new formula) }\end{array}$ & 201.7 & & 197.5 & 195.4 & \\
\hline
\end{tabular}

b) Tan observed that the difference between two consecutive recommended maximum heart rates in the table seems to be descreased when the age increased. Find a reduced formula for this difference depending on ages.

c) At which age the recommended maximum heart rates in the old formula and the new formula have the same value?

d) Compare the recommended maximum heart rates in both formulas when the age is increased. Explain your answer.

Question 12. A school class wants to rent a coach for an excursion, and three companies are contacted for information about prices.

Company A charges an initial rate of 3,750, 000 VND plus 5,000 VND per kilometre driven. 
Company B charges an initial rate of 2,500,000 VND plus 7,500 VND per kilometre driven.

Company C charges a flat rate of 3,500,000 VND up to 200 kilometres, plus 10,200 VND per kilometre beyond 200 kilometres.

a) Establish the formula representing the price of each company depending on the travelling distance.

b) At which distance are the prices of the companies A and B (resp. A and C) the same?

c) Which company should the class choose, if the excursion involves a total travel distance of somewhere between 400 and 600 kilometres? 